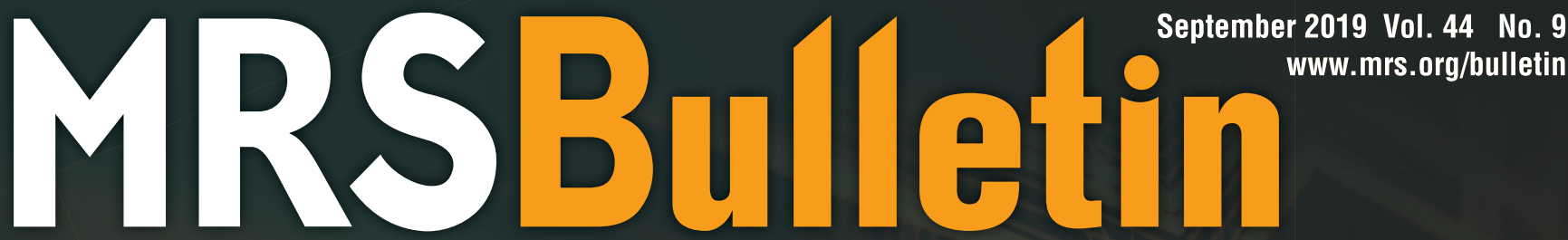

\begin{tabular}{l|l|l|l}
$M$ & $R$ & $S$ & $\begin{array}{l}\text { MATERIALS RESEARCH SOCIETY } \\
\text { Advancing materials. Improving the quality of life. }\end{array}$
\end{tabular}

\title{
Phase-change materials in electronics and photonics
}




\section{CUSTOMIZED PRODUCTION ION IMPLANTERS}

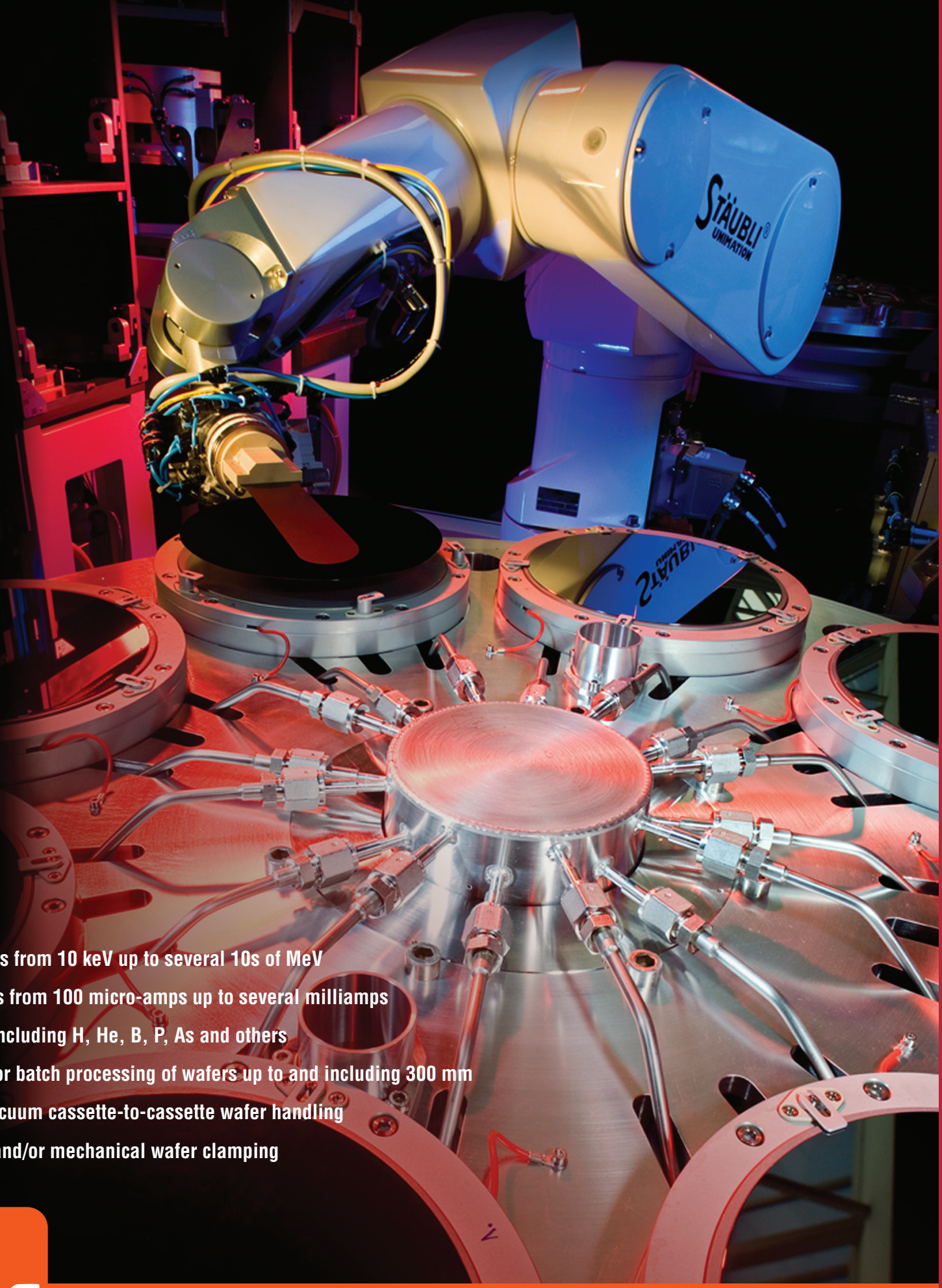

Beam energies from $10 \mathrm{keV}$ up to several $10 \mathrm{~s}$ of $\mathrm{Me}$

Beam currents from 100 micro-amps up to several milliamps

- Ion species, including $\mathrm{H}, \mathrm{He}, \mathrm{B}, \mathrm{P}, \mathrm{As}$ and others

Single wafer or batch processing of wafers up to and including $300 \mathrm{~mm}$

- In-air or in-vacuum cassette-to-cassette wafer handling

- Electrostatic and/or mechanical wafer clamping

\section{Hr High Voltage Engineering}

High Voltage Engineering Europa B.V.

P.O. Box 99, 3800 AB Amersfoort, The Netherlands

Tel: $31334619741 \cdot$ info@highvolteng.com

www.highvolteng.com 
Abstract Submission Opens September 26, 2019

Abstract Submission Deadline October 31, 2019

\section{Spring Meeting registrations include MRS Membership July 1, 2020 - June 30, 2021}

\section{CHARACTERIZATION AND THEORY}

CT01 Artificial Intelligence for Material Design, Processing and Characterizations CT02 Halide Perovskites-

From Lead-Free Materials to Advanced Characterization and Deposition Approaches

CT03 Expanding the Frontiers of Actinide Materials Science

Through Experiment and Theory

CT04 Tailored Interphases for High Strength and Functional Composites-

Advances in Experiments, Simulations and Al-Based Design

СT05 Defects, Order and Disorder in Structural and Functional Fluorite-Related Compounds

CT06 Local and Global Fluctuations in Plasticity

CT07 Micro-Assembly Technologies and Heterogeneous IntegrationFundamentals to Applications

CT08 Crystallization via Nonclassical Pathways in Synthetic, Biogenic and Geologic Environments

\section{ELECTRONICS AND PHOTONICS}

EL01 Surfaces and Interfaces in Electronics and Photonics

EL02 Advanced Manufacturing of Mixed Dimensional Heterostructures

EL03 Novel Approaches and Material Platforms for Enhanced Light-Matter Interaction, Plasmonics and Metasurfaces

EL04 Materials for Nonlinear and Nonreciprocal Photonics

EL05 Scalable Photonic Material Platforms-Applications and Manufacturing Advances

EL06 Photonic Materials for Information Processing and Computing

EL07 Fundamental Mechanisms and Materials Discovery for Brain-Inspired Computing Theory and Experiment

EL08 Neuromorphic Materials and Devices for Bioinspired Computing and Artificial Intelligence

EL09 Phase-Change Materials for Electronic and Photonic Nonvolatile Memory and Neuro-Inspired Computing

EL10 Electroactive Ceramics for Information Technologies and Flexible Electronics

EL11 Lead-Free Ferroelectrics and Their Emerging Applications

EL12 Ferroic Materials and Heterostructures for Electronics and Data Storage

EL13 Processing, Microstructure and Multifunctioning of Organic Semiconductors

EL14 New Materials Design for Organic Semiconductors Through Multimodel Characterization and Computational Techniques

EL15 Ultra-Wide Bandgap Materials, Devices and Systems

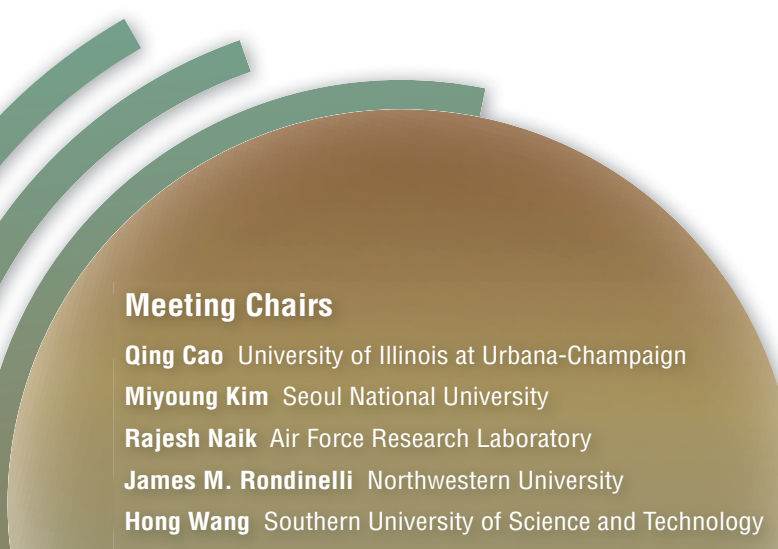

\section{Don't Miss These Future MRS Meetings!}

2020 MRS Fall Meeting \& Exhibit

November 29-December 4, 2020, Boston, Massachusetts

\author{
ENERGY, STORAGE AND CONVERSION \\ EN01 Next Steps for Perovskite Photovoltaics and Beyond \\ EN02 Caloric Materials for Sustainable Cooling Applications \\ EN03 Solar-Energy Conversion for Sustainable Water-Energy-Environmental Nexus \\ EN04 Dual-Ion Batteries as an Emerging Technology for Sustainable Energy Storage- \\ Anion Storage Materials and Full Dual-Ion Battery Devices \\ EN05 Low-Cost Aqueous Rechargeable Battery Technologies \\ EN06 Rational Designed Hierarchical Nanostructures for Photocatalytic System \\ EN07 Next-Generation Electrical Energy Storage-Beyond Intercalation-Type Lithium Ion \\ EN08 Multivalent-Based Electrochemical Energy Storage \\ EN09 Flow-Based Open Electrochemical Systems \\ EN10 Emerging Inorganic Semiconductors for Solar-Energy Conversion \\ EN11 Materials, Modeling and Technoeconomic Impacts for Large-Scale \\ Hydrogen and Energy Applications \\ EN12 Materials for Safe and Sustainable Electrochemical Energy Storage
}

\section{NANOSCALE AND QUANTUIM IMATERIALS}

NM01 Nanodiamonds-Synthesis, Properties and Applications

NM02 Colloidal Nanoparticles-From Synthesis to Applications

NM03 Nanomanipulation of Materials

NM04 Nanosafety

NM05 1D Carbon Electronics-From Synthesis to Applications

NM06 Theory and Characterization of 2D Materials-

Bridging Atomic Structure and Device Performance

NM07 Two-Dimensional Quantum Materials Out of Equilibrium

NM08 2D Atomic and Molecular Sheets-

Electronic and Photonic Properties and Device Applications

NM09 Layered van der Waals Heterostructures-

Synthesis, Physical Phenomena and Devices

NM10 Synthesis, Properties and Applications of 2D MXenes

NM11 Topological and Quantum Phenomena in Oxides and Oxide Heterostructures

NM12 Synthesis and Control of Dirac or Topological Materials

\section{SOFT MIATERIALS AND BIOMIATERIALS}

SM01 Organ-on-a-Chip-Toward Personalized Precision Medicine

SM02 Progress in Open-Space Microfluidics-

From Nanoscience, Manufacturing to Biomedicine

SM03 Flexible, Stretchable Biointegrated Materials, Devices and Related Mechanics

SM04 Fundamental Materials, Devices and Fabrication Innovations for Biointegrated and Bioinspired Electronics

SM05 Engineered Functional Multicellular Circuits, Devices and Systems

SM06 Soft Organic and Hybrid Materials for BiointerfacingMaterials, Processes and Applications

SM07 Bioinspired Synthesis and Manufacturing of Materials

SM08 Emerging Strategies and Applications in Drug Delivery

SM09 Advances in 3D Printing for Medical Applications

\section{FOLLOW THE MEETING! \\ \#S2OMRS 0 ( 9}

M R S MATERIALS RESEARCH SOCIETY Advancing materials. Improving the quality of life.

mrs.org/spring2020 



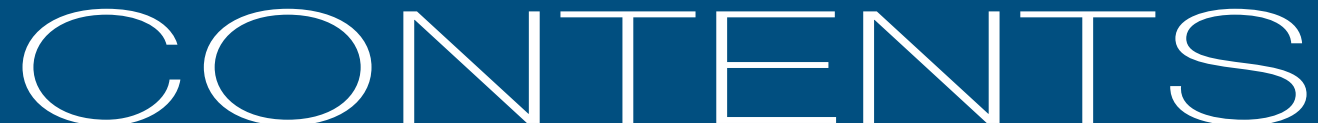

\section{PHASE-CHANGE MATERIALS IN ELECTRONICS AND PHOTONICS}

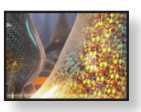

686 Phase-change materials in electronics and photonics Wei Zhang, Riccardo Mazzarello, and Evan Ma, Guest Editors

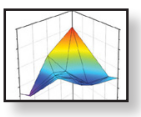

691 Phase-change materials: The view from the liquid phase and the metallicity parameter Shuai Wei, Pierre Lucas, and C. Austen Angell

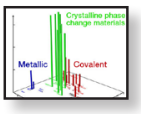

Phase-change materials: Empowered by an unconventional bonding mechanism J. Pries, 0. Cojocaru-Mirédin, and M. Wuttig

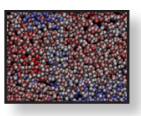

705 Harnessing machine learning potentials to understand the functional properties of phase-change materials

G.C. Sosso and M. Bernasconi

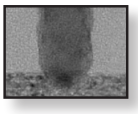

710 Phase-change memory cycling endurance SangBum Kim, Geoffrey W. Burr, Wanki Kim, and Sung-Wook Nam

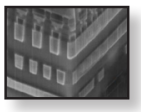

715 Ovonic threshold switching selectors for three-dimensional stackable phase-change memory Min Zhu, Kun Ren, and Zhitang Song

721 Integrated phase-change photonic devices and systems

C. David Wright, Harish Bhaskaran, and Wolfram H.P. Pernice

\section{Energy Quarterly}

\section{(1) \\ 681 Editorial \\ Time is critical for fuel-cell resurgence \\ Sossina M. Haile \\ 682 Energy Sector Analysis \\ Future energy, fuel cells, and solid-oxide fuel-cell technology \\ Nguyen Q. Minh \\ FEATURE EDITOR: Y. Shirley Meng \\ 684 Energy Sector Analysis \\ Electrolysis for hydrogen production \\ Prachi Patel \\ FEATURE EDITOR: Kathy Ayers}

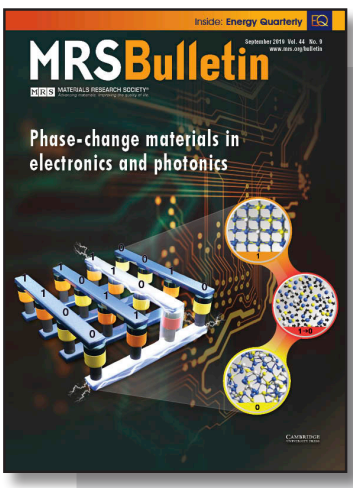

\section{ON THE COVER}

Phase-change materials in electronics and photonics. Phase-change materials (PCMs) show great promise to enable future nonvolatile memory devices and neuro-inspired computing devices that can unify computing with storage in memory cells. The articles in this issue of MRS Bulletin highlight recent breakthroughs in the fundamental materials science, as well as electronic and photonic implementations of novel devices based on PCMs. The cover shows a typical crossbar memory array that utilizes the rapid and reversible phase transitions between crystalline (logic state " 1 ," orange cells) and amorphous (logic state "0," yellow cells) PCMs to store and process data. For the " $1 \rightarrow 0$ " operation, an ordered crystalline state is first melted to a liquid state, and subsequent rapid quenching results in a disordered amorphous state. All memory cells are covered by a selector layer to improve the accuracy of memory programming through electrical pulses. Images courtesy of Yuxing Zhou, Xi'an Jiaotong University, China. See the technical theme that begins on page 686 .

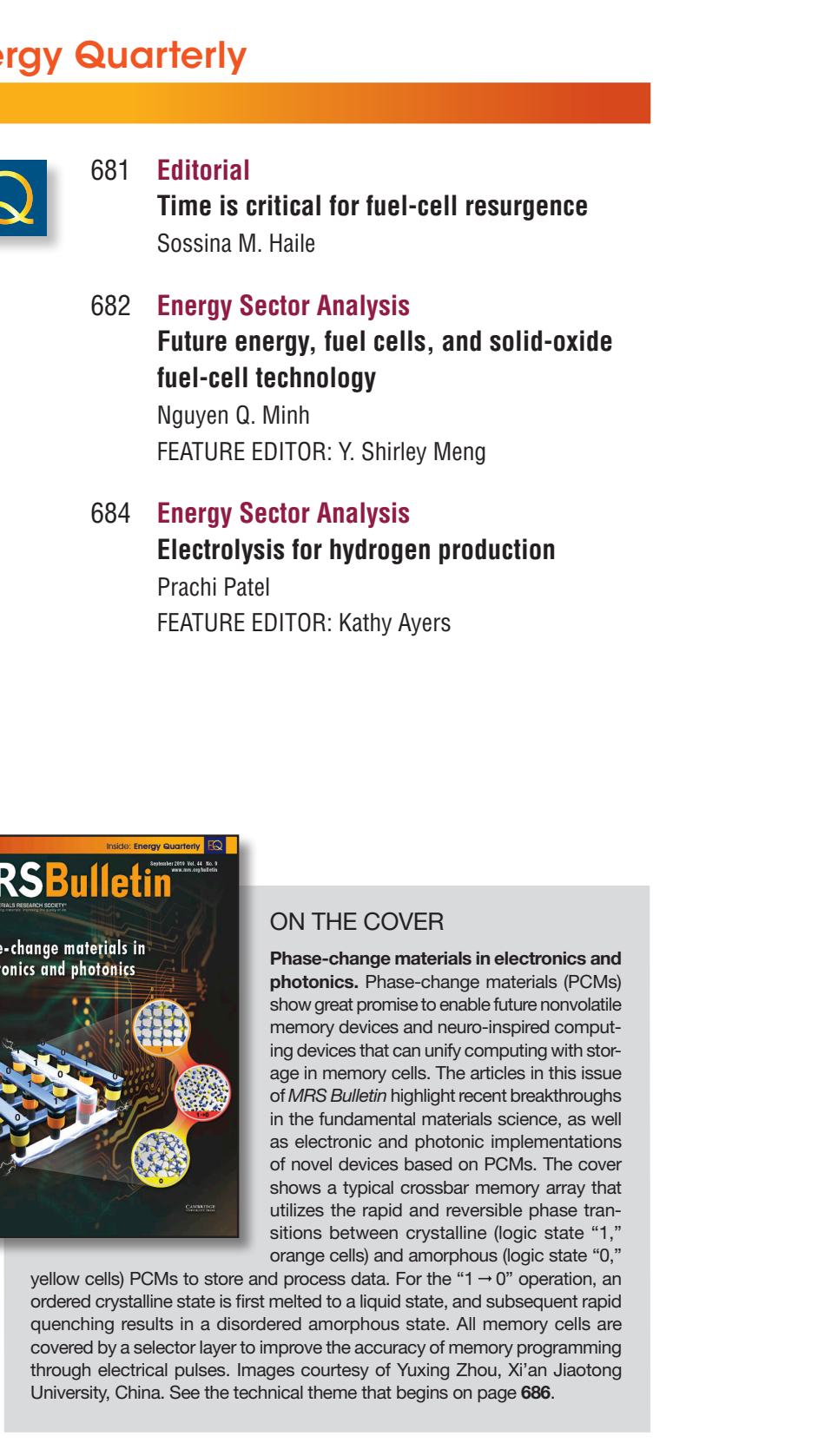




\section{DEPARTMENTS}

\section{OPINION}

669 Material Matters

A self-driving microscope and the Atomic Forge

Ondrej Dyck, Stephen Jesse, and Sergei V. Kalinin

\section{NEWS \& ANALYSIS}

673 Materials News

- Research Highlights: Perovskites

Prachi Patel

FEATURE EDITOR: Pabitra K. Nayak

- Nacre-inspired composites display optical transparency, fracture toughness Kendra Redmond

- The puzzle of water solubilities of polyethers solved Tianyu Liu

- Proteins designed to bind to a specific surface Hortense Le Ferrand

678 Science Policy

- Hard sell for metamaterials in the UK Michael Kenward

- South Korea strengthens international ties for Industry 4.0

- US Department of Energy funds R\&D for fusion

\section{SOCIETY NEWS}

\section{MRS Journal Highlights}

728 MRS University Chapter Special Project Grants offer learning and collaboration

731 Profiles

Sanjay Mathur: International advocate of sustainability Humaira Taz

732 - In memoriam: Hanns-Ulrich Habermeier

- John Robert Schrieffer, Nobel laureate, dies at $\mathbf{8 8}$
FEATURES

\section{Posterminaries \\ Inspiring students one molecule at a time \\ Frieda Wiley}

\section{CAREER CENTRAL}

\section{ADVERTISERS IN THIS ISSUE}

American Elements

High Voltage Engineering

The Kavli Foundation

Rigaku Corporation......

\section{Page No.} Outside back cover Inside front cover 


\section{$\mathrm{M}|\mathrm{R}| \mathrm{S}$}

MATERIALS RESEARCH SOCIETY ${ }^{\circledR}$

Advancing materials. Improving the quality of life.
EDITORIAL OFFICE 506 Keystone Drive, Warrendale, PA 15086-7573 USA

Bulletin@mrs.org tel 724.779.2747 fax 724.779.8313 www.mrs.org

\section{About the Materials Research Society}

The Materials Research Society (MRS), a not-for-profit scientific association founded in 1973 and headquartered in Warrendale, Pennsylvania, USA, promotes interdisciplinary materials research. Today, MRS is a growing, vibrant, member-driven organization of over 16,000 materials researchers spanning over 80 countries, from academia, industry, and government, and a recognized leader in the advancement of interdisciplinary materials research.

The Society's interdisciplinary approach differs from that of single-discipline professional societies because it promotes information exchange across many scientific and technical fields touching materials development. MRS conducts three major international annual meetings and also sponsors numerous single-topic scientific meetings. The Society recognizes professional and technical excellence and fosters technical interaction through University Chapters. In the international arena, MRS implements bilateral projects with partner organizations to benefit the worldwide materials community. The Materials Research Society Foundation helps the Society advance its mission by supporting various projects and initiatives.

\section{MRS BOARD OF DIRECTORS}

President Michael R. Fitzsimmons, Oak Ridge National Laboratory and

The University of Tennessee, USA

Immediate Past President Sean J. Hearne, Oak Ridge National Laboratory, USA

Vice President and President-Elect Matt Copel, IBM Research Division, USA

Secretary Eric A. Stach, University of Pennsylvania, USA

Treasurer David J. Parrillo, DowDuPont Industrial Intermediates

and Infrastructure, USA

Executive Director Todd M. Osman, Materials Research Society, USA

Griselda Bonilla, IBM T.J. Watson Research Center, USA

Li-Chyong Chen, National Taiwan University, Taiwan

Dawnielle Farrar-Gaines, Johns Hopkins University, USA

Claudia Gutiérrez-Wing, Instituto Nacional de Investigaciones Nucleares, Mexico Sarah Heilshorn, Stanford University, USA

Frances A. Houle, Lawrence Berkeley National Laboratory, USA

Mônica Jung de Andrade, The University of Texas at Dallas, USA

Sergei V. Kalinin, Oak Ridge National Laboratory, USA

Kisuk Kang, Seoul National University, Republic of Korea

Lincoln J. Lauhon, Northwestern University, USA

Paul C. McIntyre, Stanford University, USA

Christopher A. Schuh, Massachusetts Institute of Technology, USA

Rachel A. Segalman, University of California, Santa Barbara, USA

Molly M. Stevens, Imperial College London, UK

Yusheng Zhao, Southern University of Science and Technology, China

Ehrenfried Zschech, Fraunhofer Institute for Ceramic Technologies

and Systems, Germany

\section{MRS OPERATING COMMITTEE CHAIRS}

Academic Affairs Sanjay Mathur, University of Cologne, Germany

Awards (Co-chairs) Suveen N. Mathaudhu, University of California, Riverside, USA Judith L. MacManus-Driscoll, University of Cambridge, UK

Government Affairs David P. Norton, University of Florida, USA

Meetings Terry Aselage, Sandia National Laboratories, USA

Member Engagement Sossina M. Haile, Northwestern University, USA

Public Outreach Elizabeth Kupp, The Pennsylvania State University, USA

Publications Shefford P. Baker, Cornell University, USA

MRS HEADQUARTERS

Todd M. Osman, Executive Director

J. Ardie Dillen, Director of Finance and Administration

Damon Dozier, Director of Government Affairs

Patricia Hastings, Director of Meetings Activities

Eileen M. Kiley, Director of Communications
Editor

Gopal R. Rao, rao@mrs.org

Managing Editor

Lori A. Wilson, Iwilson@mrs.org

News Editor

Judy Meiksin, meiksin@mrs.org

Technical Editor

Lisa C. Oldham, oldham@mrs.org

Editorial Assistants

Mary Wilmoth

Associate Technical Editor

Tobias Lockwood

Production/Design

Stephanie Gabborin, Heather Shick,

Felicia Turano, and TNQ

Production Editor

Michael Dellert

Principal Development Editor

Elizabeth L. Fleischer

Director of Communications

Eileen M. Kiley
Shayla N. Poling, poling@mrs.org,
Guest Editors

Wei Zhang, Riccardo Mazzarello,

and Evan Ma

Special Consultant

Energy Quarterly Kristen Brown, David Cahen,

Russell R. Chianelli, George Crabtree,

Brian J. Ingram, Elizabeth A. Kócs,

Sabrina Sartori, Subhash L. Shinde,

Anke Weidenkaff, M. Stanley Whittingham,

Advertising/Sponsorship

Mary E. Kaufold, kaufold@mrs.org

Donna L. Watterson, watterson@mrs.org

Member Subscriptions

Michelle Judt, judt@mrs.org

Non-Member Subscriptions

subscriptions_newyork@cambridge.org
Angelika Veziridis

Y. Shirley Meng (Chair), Andrea Ambrosini, and Steve M. Yalisove

\section{EDITORIAL BOARD}

Amit Misra (Chair), University of Michigan, USA

Ilke Arslan, Pacific Northwest National Laboratory, USA

V.S. Arunachalam, Center for Study of Science, Technology \& Policy, India

N. (Balu) Balasubramanian, Bangalore, India (retired)

Christopher J. Bettinger, Carnegie Mellon University, USA

Tommie Kelley, 3M, USA

Igor Lubomirsky, Weizmann Institute, Israe

Fiona C. Meldrum, University of Leeds, UK

Steven C. Moss, The Aerospace Corporation, USA (retired)

Julie A. Nucci, Cornell University, USA

Linda J. Olafsen, Baylor University, USA

Boaz Pokroy, Technion-Israel Institute of Technology, Israel

Zhiwei Shan, Xi'an Jiaotong University and Hysitron, China

Subhash L. Shinde, University of Notre Dame, USA

James W. Stasiak, HP Inc., USA

Carol Trager-Cowan, University of Strathclyde, UK

Eric Werwa, Washington, DC, USA

M. Stanley Whittingham, Binghamton University, The State University of New York, USA

Steve M. Yalisove, University of Michigan, USA

\section{VOLUME ORGANIZERS}

2019 Craig B. Arnold, Princeton University, USA

Claus Daniel, Oak Ridge National Laboratory and The University of Tennessee, Knoxville, USA

Seung Min Han, Korea Advanced Institute of Science and Technology, Republic of Korea Gabriel Montaño, Los Alamos National Laboratory/Northern Arizona University, USA

2020 Hongyou Fan, Sandia National Laboratories, USA

Oleg Gang, Columbia University and Brookhaven National Laboratory, USA

Seokwoo Jeon, Korea Advanced Institute of Science and Technology, Republic of Korea

Tae-Woo Lee, Seoul National University, Republic of Korea

2021 Babu Chalamala, Sandia National Laboratories, USA

Paul Evans, University of Wisconsin-Madison, USA

Takao Someya, The University of Tokyo, Japan

Haiyan Wang, Purdue University, USA

MRS Bulletin (ISSN: 0883-7694, print; ISSN 1938-1425, online) is published monthly by the Materials Research Society, 506 Keystone Drive, Warrendale, PA 15086-7573. @ 2019 Materials Research Society. Permission required to reproduce content. Periodical postage paid at New York, NY, and at additional mailing offices. POSTMASTER: Send address changes to MRS Bulletin in care of the Journals Department, Cambridge University Press, 100 Brook Hill Drive, West Nyack, NY 10994-2113, USA. Printed in the U.S.A.

Membership in MRS is $\$ 130$ annually for regular members, $\$ 32$ for students, and includes an electronic subscription to MRS Bulletin. Print subscriptions are available to MRS members for an additional $\$ 25$. Individual member subscriptions are for personal use only. Non-member subscription rates are \$588 (USD) for one calendar year (12 issues). Requests from subscribers for missing journal issues will be honored without charge only if received within six months of the issue's actual date of publication.

MRS Bulletin is included in Current Contents ${ }^{\circledast} /$ Engineering, Computing, and Technology; Current Contents $\circledast /$ Physical, Chemical, and Earth Sciences, the SciSearch ${ }^{\circledast}$ online database, Research Alert ${ }^{\oplus}$, Science Citation Index ${ }^{\oplus}$, and the Materials Science Citation Index ${ }^{\mathrm{TM}}$. Back volumes of MRS Bulletin are available on microfiche through University Microfilms Inc. 300 North Zeeb Road, Ann Arbor, MI 48106, USA.

Authors of each technical article appearing in MRS Bulletin are solely responsible for all content in their article(s), including accuracy of the facts, statements, and citing resources. Facts and opinions are solely the personal statements of the respective authors and do not necessarily represent the views of the editors, the Materials Research Society, or Cambridge University Press.

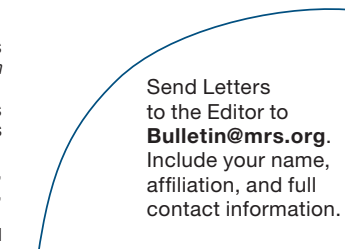

